\title{
Evaluation of Risks and Benefits of Physical Activity of Hypertensives and Normotensives: Fighting a Societal Burden
}

\author{
Rui Brás ${ }^{1,2}$, Dulce Esteves ${ }^{1,2}$, Ricardo Gouveia Rodrigues ${ }^{3,4}$, Paulo Duarte ${ }^{3,4}$, Ana Gouveia ${ }^{5,6}$, \\ Kelly O’Hara ${ }^{1}$, Paulo Pinheiro ${ }^{3,4}$ \\ Affiliations: ${ }^{1}$ University of Beira Interior, Sport Sciences Department, Covilhã, Portugal, ${ }^{2}$ Sports Sciences, \\ Health Sciences and Human Development (CIDESD), Covilhã, Portugal, ${ }^{3}$ University of Beira Interior, \\ Business and Economics Department, Covilhã, Portugal, ${ }^{4}$ Research Unit in Business Sciences (NECE - UBI), \\ Covilhã, Portugal, ${ }^{5}$ University of Beira Interior, Faculty of Health Sciences, Covilhã, Portugal, ${ }^{6}$ University of \\ Lisbon, Institute of Biophysics and Biomedical Engineering, Lisbon, Portugal
}

Correspondence: P. Duarte, University of Beira Interior, Business and Economics Department, Rua Marquês d’Ávila e Bolama, 6201-001, Covilhã, Portugal. E-mail: pduarte@ubi.pt

ABSTRACT Physical Activity (PA) is considered a coadjutant factor in the control of hypertension, helping to control this societal burden. This study investigates the factors that may influence the adoption of PA recommendations by hypertensive individuals by comparing physical activity patterns among hypertensives and normotensives and the importance placed on PA by both groups. Data from 966 Portuguese participants aged between 18 to 90 years old, representing hypertensives $(n=144)$ and normotensives $(n=822)$ were collected using a face-to-face questionnaire. The results show significant differences between the two groups in terms of causes of non-participation and dropping out, preferred PA activities, perceived knowledge, and information-seeking behaviour. The main barriers to exercise reported by hypertensives were the perception that PA is not adequate or even dangerous to their health. Doctors must be considered a key factor in promoting exercise. When compared to normotensives, hypertensives feel that PA information available is not appropriate $(\mathrm{p}=.0006)$. Hypertensives consider that existing programmes will not meet their needs and do not like traditional fitness classes, such as those in gyms. The fear of risks associated with exercise seems to be a significant barrier that impairs PA participation.

KEY WORDS hypertension, exercise, health benefits, behavioural change, barriers, risks

@MJSSMontenegro

PERCEPTION OF RISKS AND BENEFITS OF PA AMONG HYPERTENSIVES

http://mjssm.me/?sekcija=article\&artid=187

\section{Introduction}

Hypertension affects 30 to $45 \%$ of adults worldwide and is responsible for approximately $13 \%$ of all deaths (Gerage et al., 2015). It is considered a significant risk factor for severe cardiovascular disease such as myocardial infarction or stroke (Eckel et al., 2014; James et al., 2014).

Hypertension has a strong relationship to a sedentary lifestyle, high sodium and high caloric intake, high alcohol consumption, and the ageing process (Cavalcante et al., 2015; Chobanian et al., 2003). Besides medical treatment with drug prescriptions, embracing a more active lifestyle is seen as a crucial factor for managing high blood pressure in adults (Wienert, Kuhlmann, Fink, Hambrecht, \& Lippke, 2017). In fact, physical activity (PA) is present in most recommendations and treatment guidelines for hypertensive patients (James et al., 2014; Romero Blanco et al., 2015). Epidemiological studies indicate that higher PA levels are associated with lower blood pressure, and reviews of randomized controlled trials have shown that aerobic endurance training is able to control hypertension (Bakker, Sui, Brellenthin, \& Lee, 2018; Cornelissen \& Fagard, 2005). A primary physiological response to PA is post-exercise hypotension that promotes chronic adaptations and

Received: August 112019 | Accepted after revision: September 282019 | First published online: March 012020

(c) 2020 by the author(s). License MSA, Podgorica, Montenegro. This article is an open access article distributed under the terms and conditions of the Creative Commons Attribution (CC BY).

Conflict of interest: None declared. 
acute responses within the cardiovascular system. These changes have relevant clinical implications for hypertensive participants, as post-exercise hypotension can act as a nonpharmacological agent for hypertensives (Cavalcante et al., 2015). Besides post-exercise hypotension, PA has been shown to increase the capillary to fibre ratio in humans (Gliemann et al., 2015) and improve vascular function by improving the balance between vasodilator and vasoconstrictor systems (Nyberg, Gliemann, \& Hellsten, 2015).

PA promotion for hypertensive individuals, among other healthy habits (such as diet) must be a key objective of primary care for this population. To substantiate this promotion, both the American Heart Association and American College of Cardiology (Eckel et al., 2014) and the Sixth Joint Task Force of the European Society of Cardiology (Piepoli et al., 2016) developed sets of guidelines for lifestyle management to provide an evidence-based overview for lifestyle changes, namely in PA patterns, in persons diagnosed with hypertension.

Operationalizing these guidelines requires collective action by government, nongovernment, for-profit, and non-profit entities working together at several levels (Kraus et al., 2015). A systematic review on interventions for lifestyle modification based on PA and diet by Patnode, Evans, Senger, Redmond, and Lin (2017) found that interventions varied considerably across studies. Differences were identified in the behavioural focus, delivery mode, and intensity. They conclude that PA behavioural interventions were associated with modest reductions in blood pressure measures at approximately 6 to 12 months of follow-up, compared with control conditions. Another systematic review by Widmer et al. (2015) focusing on digital health interventions for the prevention of cardiovascular diseases, including hypertension, showed that no significant changes in blood pressure were found after digital interventions. Combined, the two reviews suggest that there is insufficient evidence on the effects of interventions on sedentary behaviours.

Concerning these results, the American College of Cardiology/American Heart Association Task Force (Eckel et al., 2014) considers as future research needs: to determine strategies for effectively implementing PA recommendations and increasing the understanding of factors that influence the adoption of PA recommendations. Establishing effective strategies to promote the adoption of an active lifestyle should be based on in-depth knowledge about the target population in order to customize both the promotional information and the PA implementation.

Consequently, it is essential to evaluate if there are differences between hypertensive and normotensives individuals regarding the way they seek PA information, how they perceive the PA information they already have, as well as the barriers and the objectives/expectations towards exercise. The differences should be considered in the way PA is promoted among hypertensive individuals and how the interventions must be implemented. Therefore, the specific objectives of this study are: (1) to compare physical activity patterns among hypertensives and normotensives; (2) to determine differences among PA-related information sources, and (3) to determine differences in the evidenced perception that the target groups display regarding the need and importance of PA.

\section{Methods}

This investigation is a cross-sectional population-based study in Portugal. 966 participants aged 18 to 90 years old (mean=41.9; $\mathrm{SD}=19.5$ ) were included in this study. Individuals were asked to answer several questions. Participants were recruited in public places in different areas in Portugal, in large, medium, and small cities and in rural villages. Participants were completely free to participate in the study.

The hypertension status was assessed by asking the participants if they had ever been informed by any health professional that they had high systolic or diastolic pressure (Churilla \& Ford, 2010). The participants' answers choices were (1) "yes"; (2) "yes, but only during pregnancy"; (3) "no"; and (4) "told borderline high or prehypertensive". In addition, participants were also asked if they were currently receiving any pharmacological intervention to treat hypertension. Those who answered "yes" to the hypertension question or were currently taking drugs for the high blood pressure were classified as being hypertensive (self-reported) $(\mathrm{n}=144)$. The other participants constitute the normotensive group $(\mathrm{n}=822)$. PA was assessed using the short form of the International Physical Activity Questionnaire (IPAQ) (Hagströmer, Oja, \& Sjöström, 2006). The IPAQ is validated in Portugal (Craig et al., 2003).

The barriers were adapted from Thomas, Alder, and Leese (2004). Preferred physical activities were chosen from Booth, Bauman, Owen, and Gore (2006). Goals/expectations to into account the list from the American College of Sports Medicine (2018). Perceived knowledge about PA and PA information sources were based on the study from Pinheiro, Esteves, and Brás (2012).

To ensure content and face validity, all items were reviewed by an expert panel of professors and researchers not involved in the study. The board consisted of two sports scientists, one expert researcher on market studies and survey development and one expert researcher on knowledge management. Fieldwork supervisors applied the questionnaire to 25 individuals to ensure the comprehensibility of the wording and completion time. After attending ten hours of training on the application and coding of questionnaires, nine post-graduate students collected the data.

Independent t-tests were used to examine the differences between the group means, and Levene's test to check the homoscedasticity of the groups' variances. A Chi-squared test was used to compare hypertensives with normotensives for non-metric variables. 


\section{Results}

Physical Activity Patterns among Hypertensives and Normotensives

Regarding the PA level, hypertensives showed a higher prevalence of lower and higher PA levels, but no statistically significant differences were found between hypertensives and normotensives. These results suggest the existence of two behaviours among hypertensive Portuguese adults: a more active one, already engaged in PA routines and a more sedentary one (32\%) that do not meet PA recommendations.

Considering the barriers to exercise (Figure 1), hypertensives are significantly different from normotensives in five impediments. A lack of interesting activities (53\%), do not feel empathic with other participants (42\%), not adequate to the health $(37 \%)$ and potentially dangerous to the health $(31 \%)$ are more significant barriers for the hypertensive group. The normotensives indicate a lack of time (69\%). However, lack of time, schedule and laziness are also pointed out by more than $45 \%$ of the hypertensive group, which should be considered on the promotion of PA.

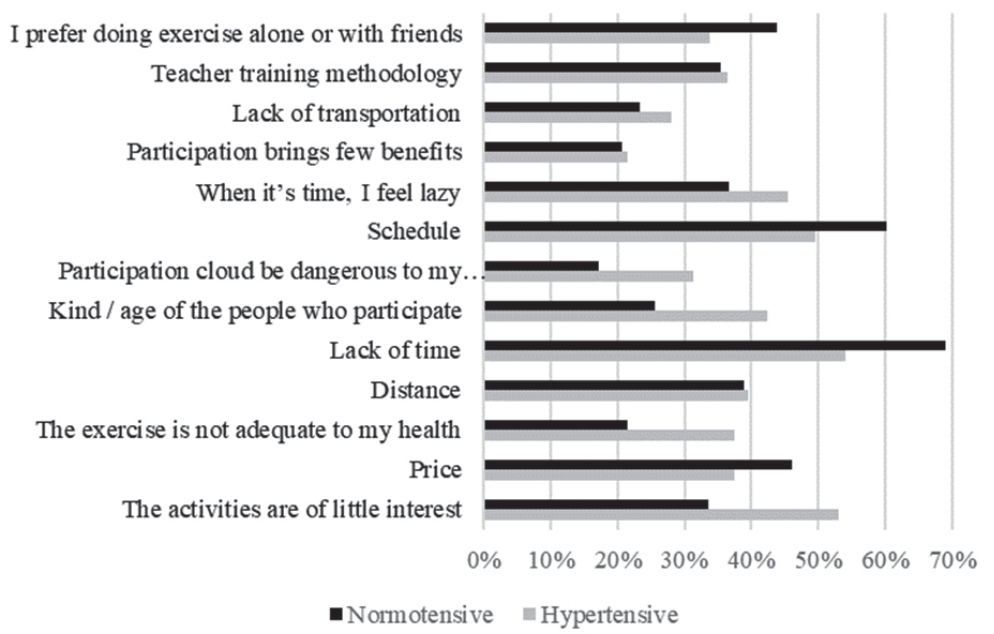

$$
\begin{aligned}
& \chi^{2}=11.266(\mathrm{p}=. \mathbf{0 0 1} *) \\
& \chi^{2}=3.092(\mathrm{p}=.079) \\
& \chi^{2}=10.679(\mathrm{p}=. \mathbf{0 0 1} *) \\
& \chi^{2}=.0012(\mathrm{p}=.913) \\
& \chi^{2}=8.291(\mathrm{p}=. \mathbf{0 0 4} *) \\
& \chi^{2}=9.969(\mathrm{p}=. \mathbf{0 0 2} *) \\
& \chi^{2}=10.727(\mathrm{p}=. \mathbf{0 0 1}) \\
& \chi^{2}=3.712(\mathrm{p}=.054) \\
& \chi^{2}=2.57(\mathrm{p}=.109) \\
& \chi^{2}=.027(\mathrm{p}=.871) \\
& \chi^{2}=1.019(\mathrm{p}=.313) \\
& \chi^{2}=.0034(\mathrm{p}=.853) \\
& \chi^{2}=3.240(\mathrm{p}=.072)
\end{aligned}
$$

Figure 1. Causes of non-participation physical activities programmes

The results of the evaluation of goals/expectations are presented in Table 1. The main goals valued by the hypertensives are learning healthy living habits (90\%), disease recovery (87\%), to become strong and more agile (79\%), prevention of diseases (76\%), and decrease stress level (75\%). The results in Table 1 showed significant differences between groups $(\mathrm{p}<.05)$ in almost all goals/expectations evaluated, but the hypertensives showed in general lower expectations about the results of participating in PA, with the exception of disease recovery $(87 \%)$ and feeling more confident $(43 \%)(\mathrm{p}<.005)$.

Concerning the preferred physical activities (Table 2), the hypertensive group answers indicated a strong preference for the meditation/mobilization classes (92\%) and walking activity (76\%). In general, this group showed a lower propensity for participation in fitness classes and using gym exercise machines, as well as

TABLE 1. Evaluation of the goals/expectations of participation in physical activities

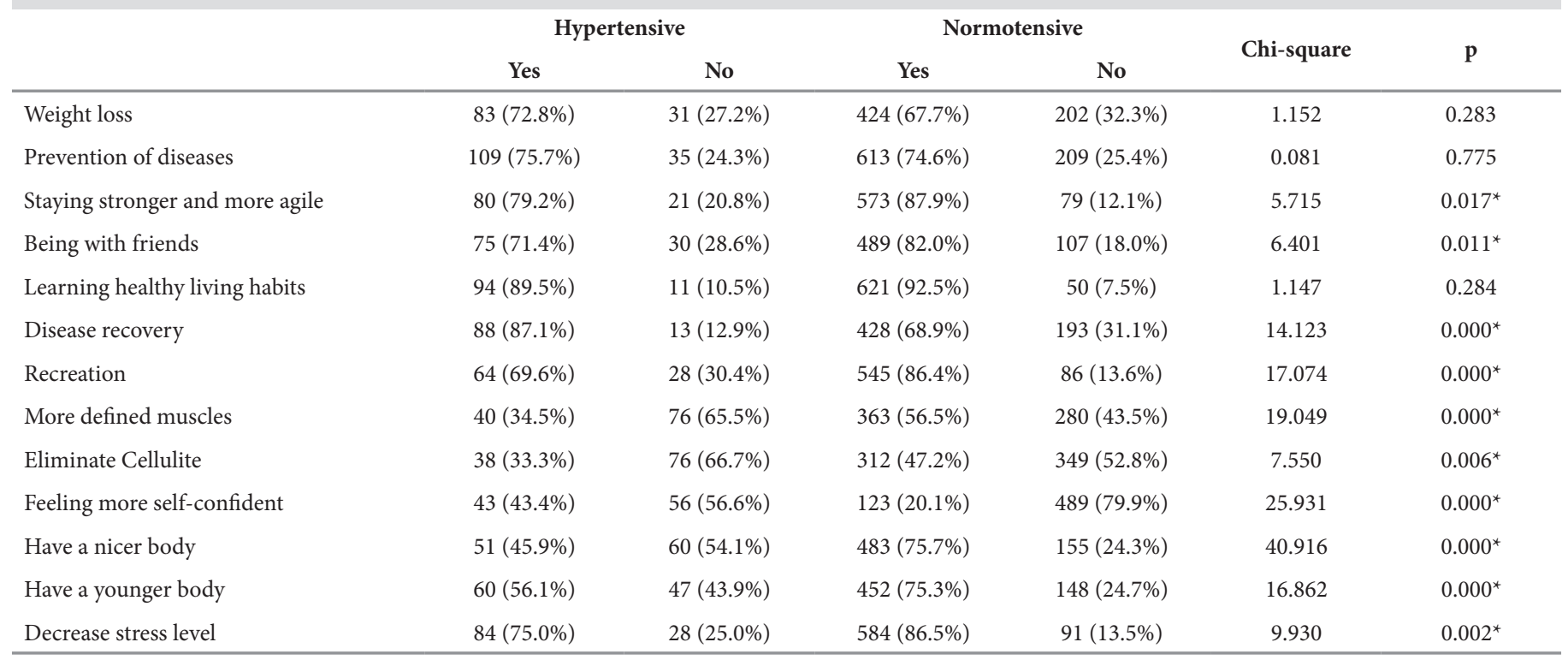

Note. ${ }^{*} \mathrm{p}<95 \%$. 
combat and extreme sports. Overall, there are significant differences between groups ( $\mathrm{p}<.005)$, with higher interest and preference of the normotensive group.

\begin{tabular}{|c|c|c|c|c|c|c|}
\hline & \multicolumn{2}{|c|}{ Hypertensive } & \multicolumn{2}{|c|}{ Normotensive } & \multirow{2}{*}{$\begin{array}{l}\text { Chi- } \\
\text { square }\end{array}$} & \multirow{2}{*}{$\mathbf{p}$} \\
\hline & Yes & No & Yes & No & & \\
\hline Walking & $\begin{array}{c}84 \\
(76.4 \%)\end{array}$ & $\begin{array}{c}26 \\
(23.6 \%)\end{array}$ & $\begin{array}{c}423 \\
(67.9 \%)\end{array}$ & $\begin{array}{c}200 \\
(32.1 \%)\end{array}$ & 3.142 & .076 \\
\hline Gym classes machines (alone) & $\begin{array}{c}18 \\
(12.5 \%)\end{array}$ & $\begin{array}{c}126 \\
(87.5 \%)\end{array}$ & $\begin{array}{c}200 \\
(24.3 \%)\end{array}$ & $\begin{array}{c}622 \\
(75.7 \%)\end{array}$ & 9.815 & $.002^{*}$ \\
\hline Aerobics classes (in group, with music) & $\begin{array}{c}33 \\
(27.7 \%)\end{array}$ & $\begin{array}{c}86 \\
(72.3 \%)\end{array}$ & $\begin{array}{c}260 \\
(38.6 \%)\end{array}$ & $\begin{array}{c}414 \\
(61.4 \%)\end{array}$ & 5.106 & $.024^{*}$ \\
\hline Structured classes (fitness) (with guidance) & $\begin{array}{c}19 \\
(15.8 \%)\end{array}$ & $\begin{array}{c}101 \\
(84.2 \%)\end{array}$ & $\begin{array}{c}253 \\
(38.0 \%)\end{array}$ & $\begin{array}{c}413 \\
(62.0 \%)\end{array}$ & 22.053 & $.000^{*}$ \\
\hline Free classes in the gym (alone) & $\begin{array}{c}22 \\
(17.5 \%)\end{array}$ & $\begin{array}{c}104 \\
(82.5 \%)\end{array}$ & $\begin{array}{c}204 \\
(31.3 \%)\end{array}$ & $\begin{array}{c}447 \\
(68.7 \%)\end{array}$ & 9.855 & $.002^{*}$ \\
\hline Outdoor classes (outdoor activities) & $\begin{array}{c}47 \\
(42.3 \%)\end{array}$ & $\begin{array}{c}64 \\
(57.7 \%)\end{array}$ & $\begin{array}{c}392 \\
(63.7 \%)\end{array}$ & $\begin{array}{c}223 \\
(36.3 \%)\end{array}$ & 18.010 & $.000^{*}$ \\
\hline Amateur sports with friends & $\begin{array}{c}31 \\
(27.0 \%)\end{array}$ & $\begin{array}{c}84 \\
(73.0 \%)\end{array}$ & $\begin{array}{c}385 \\
(55.7 \%)\end{array}$ & $\begin{array}{c}306 \\
(44.3 \%)\end{array}$ & 32.653 & $.000^{*}$ \\
\hline Structured amateur sports (with coach) & $\begin{array}{c}15 \\
(13.5 \%)\end{array}$ & $\begin{array}{c}96 \\
(86.5 \%)\end{array}$ & $\begin{array}{c}218 \\
(36.6 \%)\end{array}$ & $\begin{array}{c}378 \\
(63.4 \%)\end{array}$ & 22.527 & $.000^{*}$ \\
\hline Classes of combat modalities & $\begin{array}{c}11 \\
(8.3 \%)\end{array}$ & $\begin{array}{c}121 \\
(91.7 \%)\end{array}$ & $\begin{array}{c}107 \\
(15.5 \%)\end{array}$ & $\begin{array}{c}583 \\
(84.5 \%)\end{array}$ & 4.638 & $.031^{*}$ \\
\hline Classes of mobilization / meditation & $\begin{array}{c}115 \\
(92.0 \%)\end{array}$ & $\begin{array}{c}10 \\
(8.0 \%)\end{array}$ & $\begin{array}{c}568 \\
(83.8 \%)\end{array}$ & $\begin{array}{c}110 \\
(16.2 \%)\end{array}$ & 5.616 & $.018^{*}$ \\
\hline Dance classes & $\begin{array}{c}31 \\
(24.8 \%)\end{array}$ & $\begin{array}{c}94 \\
(75.2 \%)\end{array}$ & $\begin{array}{c}244 \\
(34.3 \%)\end{array}$ & $\begin{array}{c}468 \\
(65.7 \%)\end{array}$ & 4.322 & $.038^{*}$ \\
\hline Extreme sports in nature & $\begin{array}{c}14 \\
(11.1 \%)\end{array}$ & $\begin{array}{c}112 \\
(88.9 \%)\end{array}$ & $\begin{array}{c}290 \\
(43.2 \%)\end{array}$ & $\begin{array}{c}382 \\
(56.8 \%)\end{array}$ & 46.198 & $.000^{*}$ \\
\hline Urban extreme sports & $\begin{array}{c}21 \\
(17.4 \%)\end{array}$ & $\begin{array}{c}100 \\
(82.6 \%)\end{array}$ & $\begin{array}{c}223 \\
(34.4 \%)\end{array}$ & $\begin{array}{c}426 \\
(65.6 \%)\end{array}$ & 13.624 & $.000^{*}$ \\
\hline Traditional Games & $\begin{array}{c}57 \\
(50.9 \%)\end{array}$ & $\begin{array}{c}55 \\
(49.1 \%)\end{array}$ & $\begin{array}{c}224 \\
(38.4 \%)\end{array}$ & $\begin{array}{c}360 \\
(61.6 \%)\end{array}$ & 6.136 & $.013^{*}$ \\
\hline
\end{tabular}

Note. ${ }^{*} \mathrm{p}<95 \%$.

\section{Differences in PA-related information sources}

Since information about PA benefits, risks and recommendations is a critical factor for hypertensives to embrace an active lifestyle, PA information-seeking behaviour was analysed. Table 3 shows that only $44 \%$ of the hypertensive individuals seek information about the type of physical activity that is appropriate for them, against $61 \%$ of normotensive participants $\left(x^{2}=10,575, \mathrm{p}=.0001\right)$. Doctors are the preferred source of information for hypertensives who rely less on Internet sites and on sports professionals. Online social media is not extensively used as a PA information source by both groups, suggesting that online PA promotion campaigns may not be adequate to reach hypertensives.

TABLE 3. Information seeking about physical activity

\begin{tabular}{|c|c|c|c|c|c|c|c|}
\hline & Levene's F & $\begin{array}{l}\text { Levene's } \\
\text { p-value }\end{array}$ & $\begin{array}{c}\text { Mean } \\
\text { Hypertensive }\end{array}$ & $\begin{array}{c}\text { Mean } \\
\text { Normotensive }\end{array}$ & $\mathbf{t}$ & df & t-test's p-value \\
\hline By my doctor & 1.446 & .229 & 3.23 & 2.60 & 4.617 & 962 & $0.000^{*}$ \\
\hline By friends/family & 4.540 & .033 & 2.71 & 3.06 & -3.125 & 960 & $0.001 *$ \\
\hline By the Internet sites & 33.906 & .000 & 1.86 & 2.57 & -6.689 & 956 & $0.000^{*}$ \\
\hline By the Internet social media & 15.136 & .000 & 1.71 & 2.22 & -4.950 & 957 & $0.000^{*}$ \\
\hline By a sports professional & .884 & .347 & 2.50 & 3.21 & -5.742 & 959 & $0.000^{*}$ \\
\hline By newspaper/magazines & .696 & .404 & 2.33 & 2.46 & -1.174 & 959 & 0.242 \\
\hline
\end{tabular}

Note. ${ }^{*} \mathrm{p}<95 \%$. 
Differences in the perception of the need and importance of PA.

The perception of PA knowledge was also evaluated (Table 4). Hypertensives seem to be less secure with what they know about the benefits of PA ( $\mathrm{p}=.0002)$ but highly interested to know more about what kind of PA is right for them (84\%). The results in Table 4 also show that hypertensives $(27 \%)$ have a stronger feeling that PA information is not appropriate for their condition than normotensives do (16\%) ( $\mathrm{p}=.0006)$. Both groups found that the information they receive is not clear.

TABLE 4. Perceived knowledge about physical activity

\begin{tabular}{|c|c|c|c|c|c|c|}
\hline & \multicolumn{2}{|c|}{ Hypertensive } & \multicolumn{2}{|c|}{ Normotensive } & \multirow{2}{*}{ Chi-square } & \multirow{2}{*}{$\mathbf{p}$} \\
\hline & Yes & No & Yes & No & & \\
\hline Know the benefits that PA brings to my life. & $82(83.7 \%)$ & $16(16.9 \%)$ & $615(93.0 \%)$ & $46(7.0 \%)$ & 9.983 & $0.002^{*}$ \\
\hline $\begin{array}{l}\text { Would like to know more about the benefits that PA } \\
\text { brings to my life. }\end{array}$ & $81(56.3 \%)$ & $63(43.8 \%)$ & $525(64.0 \%)$ & $295(36.0 \%)$ & 3.171 & 0.075 \\
\hline $\begin{array}{l}\text { Would like to know more about what kind of PA is right } \\
\text { for me. }\end{array}$ & $90(84.1 \%)$ & $17(15.9 \%)$ & $566(89.8 \%)$ & $64(10.2 \%)$ & 3.069 & 0.080 \\
\hline $\begin{array}{l}\text { Believe the information on PA I receive is correct and I } \\
\text { trust them }\end{array}$ & $59(72.0 \%)$ & $23(28.0 \%)$ & $421(81.0 \%)$ & $99(19.0 \%)$ & 3.559 & 0.059 \\
\hline $\begin{array}{l}\text { Find that the information on } \mathrm{PA} \text { I receive is not clear, and } \\
\text { often do not understand it }\end{array}$ & $18(20.5 \%)$ & $70(79.5 \%)$ & $111(18.3 \%)$ & $495(81.7 \%)$ & 0.232 & 0.630 \\
\hline $\begin{array}{l}\text { Find that the information on PA I receive is not appropri- } \\
\text { ate for my age/condition, so it's not useful }\end{array}$ & $27(26.7 \%)$ & $74(73.3 \%)$ & $100(15.7 \%)$ & $537(84.3 \%)$ & 7.450 & $0.006^{*}$ \\
\hline
\end{tabular}

Note.df $=1$.

\section{Discussion}

Regular PA is considered a cornerstone in the prevention and management of hypertension due to its cardiovascular system benefits (Eckel et al., 2014; James et al., 2014; Piepoli et al., 2016). Although the PA recommendations for hypertension are well established, previous studies seem to indicate that there is no significant change in hypertensives' PA behaviours (Churilla \& Ford, 2010; Patnode et al., 2017). The strategies for PA promotion and the interventions need in-depth knowledge about the hypertensive population to increase acceptance and adherence to PA programmes (Gallegos-Carrillo et al., 2014). Therefore, understanding what hypertensives think and knowing what the specific barriers preventing them from searching for information and engaging in PA are vital.

Self-reported data suggest that about one-third of adults globally are not meeting the necessary PA recommendations to be healthily active (Hallal et al., 2012). In this study, no differences were observed between groups regarding the PA level; consequently, it challenges previous studies suggesting that a sedentary lifestyle is associated with hypertension incidence (Jakes et al., 2003; Twinamasiko et al., 2018). The interaction with other significant hypertension factors, such as age, tobacco use, stress, dietary sodium, alcohol consumption, dyslipidaemia, or overweight and obesity that have been shown to be independent risk factors for the hypertension development should be explored (Hu et al., 2004).

The current results, although not significant, showed that the hypertensives are more sedentary (low-level PA) (31\%) than the normotensives are $(20 \%)$, but these results must be correlated with other risk factors. Nevertheless, the current study outcomes evidence that the Portuguese hypertensive population needs an effective PA strategy intervention since the protective effects of PA in hypertension prevention and management have been well demonstrated (Piepoli et al., 2016). Additionally, it is important to note that $40 \%$ of hypertensives self-reported high levels of PA, which could mean that there is a sub-group of hypertensive Portuguese adults that is physically active. These results are lower than the ones obtained by Churilla and Ford (2010), showing that $60 \%$ of self-reported American hypertensives accomplish the international physical activity recommendations (American College of Sports Medicine, 2018). The same proportion was observed by Romero Blanco et al. (2015) on a sample of Spanish hypertensives. The IPAQ survey used to assess PA level considers not only the amount of PA time (min/week) but also the frequency of PA to estimate the Metabolic Equivalent (METs). Therefore, an individual who reports 150 min of running 1 day per week would meet the international PA recommendations, but the calculated score IPAQ will correspond only to a moderate level because of the 1-day volume.

Regular exercise is recognized as a significant modifiable cause of hypertension (Pescatello, MacDonald, Lamberti, \& Johnson, 2015). Understanding the influence of specific barriers to engage in exercise programmes is decisive in designing PA promotion strategies. The causes of non-participation or drop out presented in Figure 1 indicate that the hypertensives believe that physical activities (53\%) and the profile of programmes $(42 \%)$ are not very interesting $(\mathrm{p}<.005)$, suggesting that hypertensives do not have a positive perception about PA programmes. Moreover, compared to normotensives, hypertensives also report lower expectations towards exercise benefits. This issue will require better information about PA programmes, the adaptation of physical exercise to individual preferences, and inviting hypertensives to experiment with different types of exercises. Furthermore, since many of the hypertensives do not have a favourable social and family support to 
engage or maintain on PA programmes (Gong et al., 2018) it is vital that PA programmes should be designed to nurture social integration.

Health-related barriers were also quoted as a significant obstacle for the hypertensives when compared to the normotensives. Despite the hypertension benefits of PA, particularly aerobic exercise, have been well established (Bakker et al., 2018), 37\% of the self-reported hypertensive participants considered that exercise is not adequate for their health and $31 \%$ believed that exercise could even be dangerous for their health (31\%) $(\mathrm{p}<.005)$. However, $87 \%$ indicated "Disease recovery" as the main PA participation goal $(\mathrm{p}=.000)$, which means that the hypertensives do not fully trust the health benefits of exercise. These results reinforce the need for better education and more information about the specifics benefits of PA on hypertension treatment.

The preferred physical activities by hypertensives were meditation/mobilization classes, walking or traditional games $(\mathrm{p}<.005)$, activities that demand a low or moderate level of effort. The less preferred ones were gym classes, machines, and fitness classes, as well as combat and extreme sports. Based on this evidence, a PA promotional strategy should incorporate activities that are energy less demanding and not require high skills. Only after the individual feels more self-confident and secure about the benefits of the PA is it possible to promote more demanding physical exercises and proceed with promoting additional healthy living habits. Appearance-related issues seem to be less important, so they should not be a priority for the communication strategy but must not be totally ignored.

Regarding PA information seeking, hypertensives search for less information than normotensives do, and they prefer doctors as the primary and almost sole information source. Health professionals working in primary health care have an essential role in promoting PA and healthy lifestyle due to their intimacy with hypertensive individuals (Gallegos-Carrillo et al., 2014; Plotnikoff, Johnson, Karunamuni, \& Boule, 2010). However, a systematic review conducted by Hébert, Caughy, and Shuval (2012) shows that these professionals do not feel confident or properly trained to provide more than general advice about PA. Therefore, a PA promotion campaign targeting hypertensives must involve primary care staff who must be prepared to demystify the barriers that prevent the adoption of PA by hypertensives.

The findings suggest that online campaigns seem to be very little used by both groups despite the fact that websites, online tutorials, or social networking sites are the platforms most used to increase PA (Burke et al., 2015). A recent pilot study about the efficacy of a mobile application platform showed short-term potential to reduce the risk of hypertension (Toro-Ramos et al., 2017); the success of this digital programme was based a structured educational content and a live interaction with trained coaches and group motivation with peers, in order to realize the necessary lifestyle changes.

Hypertensives do not usually seek for PA information, but they want to know more about what kind of PA is adequate for them (84\%). Moreover, compared to the normotensives, the hypertensive group acknowledge having low knowledge about PA benefits ( $\mathrm{p}=.0002)$. The results suggest that hypertensives require more information, and probably provide stronger evidence of the gains associated with the increase of PA. Based on this, it is recommended that the PA promotion strategies should highlight information on the benefits to help hypertensives to adopt more active behaviour.

\section{Conclusions}

This research aimed to increase knowledge about the factors that determine PA adoption by hypertensives. Based on the results, it is concluded that the fear of risks associated with exercise seems to be a significant barrier that impairs PA participation. In fact, hypertensives tend to prefer activities like walking, outdoor activities, classes of mobilization/meditation, and traditional games, displaying a lower propensity for participation in fitness classes. Since hypertensives do not like traditional fitness classes, gym owners should develop programmes that meet both the preferences, fears and expectations of this target. They should also adequately promote these programmes, emphasizing their safety and benefits to blood pressure (BP) management. The perception of potential risks may be considerably minimized by stressing the benefits of specifically designed, personalized, and supervised PA.

The main barriers to exercise reported by hypertensives were the perception that physical activities are not adequate or even potentially dangerous to their health; therefore, doctors must be considered a critical factor in promoting exercise. However, it is not enough to recommend exercise; guidelines should also be provided regarding the participation in specific PA programmes.

The main expectations that this population has on exercise is learning healthy habits, disease recovery and prevention, and mobility improvement. However, hypertensives think that existing programmes do not fulfil these. To assess their knowledge of the existing options the sources of information on PA were assessed, and the conclusion is that hypertensive individuals seek less information about physical activity than normotensives do and that physicians are the preferred sounds information for the promotion of an active lifestyle. Despite understanding the importance of BP control for their health, they seem to display some negligent behaviour regarding the knowledge of which BP is appropriate to their specific condition and the gains they could achieve. Governmental health organizations should consider implementing specific physical activity programmes for hypertensive individuals and communicate them with the endorsement of physicians using 
the available online and offline channels.

Finally, the behaviour of hypertensive patients was compared to normotensives to evaluate if there are differences that justify a specific strategy for hypertension. The conclusion is that there are differences significant enough to justify the development of specific exercise programmes for a hypertense population, but it is necessary that they are communicated in an appropriate way to be effective.

To summarize, the literature clearly indicates that the society in general and hypertensives' health condition would benefit from an active lifestyle and that PA is an essential factor for managing high blood pressure. However, the knowledge of physical activity patterns by hypertensives and on their perception of barriers and perceived knowledge on the benefits is scarce. This study closes the gap on the knowledge regarding how hypertensives evaluate physical activity programmes by showing that hypertensive individuals think that exercise is not safe for their health condition and present lower expectation towards exercise. However, they show signs of wanting to know more about what kind of PA is right for their condition by obtaining trustworthy and understandable information. Therefore, this study is significant as it establishes the basis for the development of more effective and tailored communication strategies to promote PA among hypertensive individuals by revealing the fears to address, barriers to overcome, and the best channels and more reliable information sources to use.

This study has a set of potential limitations that could be addressed in future research. First, causal inference is limited since it is a cross-sectional study design, and confirming these findings in future interventional studies will be required. Second, the final survey results from the adaptation of several questionnaires not extensively used, which limits the comparison with previous studies. Third, the age range sample is very large, which may be associated with different profiles of the hypertensive individuals interviewed, and this may constitute a limitation on the findings.

\section{REFERENCES}

American College of Sports Medicine. (2018). ACSM's guidelines for exercise testing and prescription. In Lippincott Williams \& Wilkins (Tenth edit). Philadelphia: Wolters Kluwer Health.

Bakker, E. A., Sui, X., Brellenthin, A. G., \& Lee, D. (2018). Physical activity and fitness for the prevention of hypertension. Current Opinion in Cardiology, 33(4), 394-401. doi: 10.1097/HCO.0000000000000526

Booth, M. L., Bauman, A., Owen, N., \& Gore, C. J. (1997). Physical Activity Preferences, Preferred Sources of Assistance, and Perceived Barriers to Increased Activity among Physically Inactive Australians. Preventive Medicine, 26(1), 131-137. doi: 10.1006/pmed.1996.9982

Burke, L. E., Ma, J., Azar, K. M. J., Bennett, G. G., Peterson, E. D., Zheng, Y., ... Quinn, C. C. (2015). Current Science on Consumer Use of Mobile Health for Cardiovascular Disease Prevention. Circulation, 132(12), 1157-1213. doi: 10.1161/CIR.0000000000000232

Cavalcante, P. A., Rica, R., Evangelista, A., Serra, A., Pontes Junior, F., Kilgore, L., ... Figueira Junior, A. (2015). Effects of exercise intensity on postexercise hypotension after resistance training session in overweight hypertensive patients. Clinical Interventions in Aging, 10, 1487. doi: 10.2147/CIA.S79625

Chobanian, A. V., Bakris, G. L., Black, H. R., Cushman, W. C., Green, L. A., Izzo, J. L., ... Roccella, E. J. (2003). Seventh report of the Joint National Committee on Prevention, Detection, Evaluation, and Treatment of High Blood Pressure. Hypertension, 42(6), 1206-1252. doi: 10.1161/01.HYP.0000107251.49515.c2

Churilla, J. R., \& Ford, E. S. (2010). Comparing Physical Activity Patterns of Hypertensive and Nonhypertensive US Adults. American Journal of Hypertension, 23(9), 987-993. doi: 10.1038/ajh.2010.88

Cornelissen, V. A., \& Fagard, R. H. (2005). Effects of Endurance Training on Blood Pressure, Blood PressureRegulating Mechanisms, and Cardiovascular Risk Factors. Hypertension, 46(4), 667-675. doi: 10.1161/01. HYP.0000184225.05629.51

Craig, C. L., Marshall, A. L., Sjöström, M., Bauman, A. E., Booth, M. L., Ainsworth, B. E., ... Oja, P. (2003). International physical activity questionnaire: 12 -Country reliability and validity. Medicine and Science in Sports and Exercise, 35(8), 1381-1395. doi: 10.1249/01.MSS.0000078924.61453.FB

Eckel, R. H., Jakicic, J. M., Ard, J. D., De Jesus, J. M., Houston Miller, N., Hubbard, V. S., ... Yanovski, S. Z. (2014). 2013 AHA/ACC guideline on lifestyle management to reduce cardiovascular risk: A report of the American college of cardiology/American heart association task force on practice guidelines. Journal of the American College of Cardiology, 63(25 PART B), 2960-2984. doi: 10.1016/j.jacc.2013.11.003

Gallegos-Carrillo, K., García-Peña, C., Salmerón, J., Salgado-de-Snyder, V. N., Vázquez-Cabrer, G., \& Lobelo, F. (2014). Exercise-referral scheme to promote physical activity among hypertensive patients: design of a cluster randomized trial in the Primary Health Care Units of Mexico's Social Security System. BMC Public Health, 14(1), 706. doi: 10.1186/1471-2458-14-706

Gerage, A. M., Benedetti, T. R. B., Farah, B. Q., Santana, F. da S., Ohara, D., Andersen, L. B., \& Ritti-Dias, R. M. (2015). Sedentary Behavior and Light Physical Activity Are Associated with Brachial and Central Blood Pressure in Hypertensive Patients. Plos One, 10(12), e0146078. doi: 10.1371/journal.pone.0146078

Gliemann, L., Buess, R., Nyberg, M., Hoppeler, H., Odriozola, A., Thaning, P., ... Mortensen, S. P. (2015). Capillary growth, ultrastructure remodelling and exercise training in skeletal muscle of essential hypertensive patients. Acta Physiologica, 214(2), 210-220. doi: 10.1111/apha.12501

Gong, J., Xu, Y., Chen, X., Yang, N., Li, F., \& Yan, Y. (2018). Persistent effect at 30-month post intervention of a community-based randomized trial of $\mathrm{KM} 2 \mathrm{H} 2 \mathrm{in}$ reducing stroke and heart attack among senior 
hypertensive patients. International Journal of Behavioral Nutrition and Physical Activity, 15(1), 1-12. doi: 10.1186/s12966-017-0635-3

Hagströmer, M., Oja, P., \& Sjöström, M. (2006). The International Physical Activity Questionnaire (IPAQ): a study of concurrent and construct validity. Public Health Nutrition, 9(06), 755-762. doi: 10.1079/ PHN2005898

Hallal, P. C., Andersen, L. B., Bull, F. C., Guthold, R., Haskell, W., \& Ekelund, U. (2012). Global physical activity levels: surveillance progress, pitfalls, and prospects. The Lancet, 380(9838), 247-257. doi: 10.1016/ S0140-6736(12)60646-1

Hébert, E. T., Caughy, M. O., \& Shuval, K. (2012). Primary care providers' perceptions of physical activity counselling in a clinical setting: a systematic review. British Journal of Sports Medicine, 46(9), 625-631. doi: 10.1136/bjsports-2011-090734

Hu, G., Barengo, N. C., Tuomilehto, J., Lakka, T. A., Nissinen, A., \& Jousilahti, P. (2004). Relationship of Physical Activity and Body Mass Index to the Risk of Hypertension: A Prospective Study in Finland. Hypertension, 43(1), 25-30. doi: 10.1161/01.HYP.0000107400.72456.19

Jakes, R. W., Day, N. E., Khaw, K.-T., Luben, R., Oakes, S., Welch, A., ... Wareham, N. J. (2003). Television viewing and low participation in vigorous recreation are independently associated with obesity and markers of cardiovascular disease risk: EPIC-Norfolk population-based study. European Journal of Clinical Nutrition, 57(9), 1089-1096. doi: 10.1038/sj.ejcn.1601648

James, P. A., Oparil, S., Carter, B. L., Cushman, W. C., Dennison-Himmelfarb, C., Handler, J., ... Ortiz, E. (2014). 2014 Evidence-Based Guideline for the Management of High Blood Pressure in Adults. JAMA, 311(5), 507. doi: 10.1001/jama.2013.284427

Kraus, W. E., Bittner, V., Appel, L., Blair, S. N., Church, T., Després, J. P., ... Whitsel, L. (2015). The National Physical Activity Plan: A Call to Action from the American Heart Association A Science Advisory from the American Heart Association. Circulation, 131(21), 1932-1940. doi: 10.1161/CIR.0000000000000203

Nyberg, M., Gliemann, L., \& Hellsten, Y. (2015). Vascular function in health, hypertension, and diabetes: Effect of physical activity on skeletal muscle microcirculation. Scandinavian Journal of Medicine and Science in Sports, Vol. 25, pp. 60-73. doi: 10.1111/sms.12591

Patnode, C. D., Evans, C. V., Senger, C. A., Redmond, N., \& Lin, J. S. (2017). Behavioral Counseling to Promote a Healthful Diet and Physical Activity for Cardiovascular Disease Prevention in Adults Without Known Cardiovascular Disease Risk Factors. Jama, 318(2), 175. doi: 10.1001/jama.2017.3303

Pescatello, L. S., MacDonald, H. V., Lamberti, L., \& Johnson, B. T. (2015). Exercise for Hypertension: A Prescription Update Integrating Existing Recommendations with Emerging Research. Current Hypertension Reports, 17(11), 87. doi: 10.1007/s11906-015-0600-y

Piepoli, M. F., Hoes, A. W., Agewall, S., Albus, C., Brotons, C., Catapano, A. L., ... Verschuren, W. M. M. (2016). 2016 European Guidelines on cardiovascular disease prevention in clinical practice. Atherosclerosis, 252, 207-274. doi: 10.1016/j.atherosclerosis.2016.05.037

Pinheiro, P., Esteves, D., \& Brás, R. (2012). Effect of Internet and social networks on knowledge regarding physical activity. The International Journal of Management Science and Information Technology (IJCSIT), $4(4), 29-41$

Plotnikoff, R. C., Johnson, S. T., Karunamuni, N., \& Boule, N. G. (2010). Physical activity related information sources predict physical activity behaviors in adults with type 2 diabetes. Journal of Health Communication, 15(8), 846-858. doi: 10.1080/10810730.2010.522224

Romero Blanco, C., Villalvilla Soria, D. J., Cabanillas Cruz, E., Laguna Nieto, M., Aznar Laín, S., Blanco, C. R., ... Lain, S. A. (2015). Cumplimiento de las recomendaciones de actividad física para la salud en adultos hipertensos. Nutricion Hospitalaria, 31(1), 415-420. doi: 10.3305/nh.2015.31.1.7423

Thomas, N., Alder, E., \& Leese, G. P. (2004). Barriers to physical activity in patients with diabetes. Postgraduate Medical Journal, 80(943), 287-291. doi: 10.1136/pgmj.2003.010553.

Toro-Ramos, T., Kim, Y., Wood, M., Rajda, J., Niejadlik, K., Honcz, J., ... Michaelides, A. (2017). Efficacy of a mobile hypertension prevention delivery platform with human coaching. Journal of Human Hypertension, 31(12), 795-800. doi: 10.1038/jhh.2017.69

Twinamasiko, B., Lukenge, E., Nabawanga, S., Nansalire, W., Kobusingye, L., Ruzaaza, G., \& Bajunirwe, F. (2018). Sedentary Lifestyle and Hypertension in a Periurban Area of Mbarara, South Western Uganda: A Population Based Cross Sectional Survey. International Journal of Hypertension, 2018, 1-8. doi: $10.1155 / 2018 / 8253948$

Widmer, R. J., Collins, N. M., Collins, C. S., West, C. P., Lerman, L. O., \& Lerman, A. (2015). Digital Health Interventions for the Prevention of Cardiovascular Disease: A Systematic Review and Meta-analysis. Mayo Clinic Proceedings, 90(4), 469-480. doi: 10.1016/j.mayocp.2014.12.026

Wienert, J., Kuhlmann, T., Fink, S., Hambrecht, R., \& Lippke, S. (2017). Motivational and Volitional Correlates of Physical Activity in Participants Reporting No, Past, and Current Hypertension: Findings from a CrossSectional Observation Study. International Journal of Behavioral Medicine, 24(6), 908-914. doi: 10.1007/ s12529-017-9649-0 